\title{
Using a Novel Cheap Rhizotron for Root Growth System Analyses on Chickpea and Lentil Plants
}

\author{
Seyed Saeid Hojjat* \\ Research Center for Plant Sciences, Ferdowsi University of Mashhad, Mashhad, Iran
}

*Corresponding author: Seyed Saeid Hojjat, Research Center for Plant Sciences, Ferdowsi University of Mashhad, Mashhad, Iran.
Received Date: October 27, 2020

Published Date: December 03, 2020

\begin{abstract}
A much better understanding of root system development and Measuring fine root growth is significant to the understanding of ecosystem structure and function and in predicting how ecosystems react to climate changeability. Their study, however, is hampered by their underground development, and characterizing complex root system architecture, hence, remains a challenge. Nowadays, a number of methods have been utilized to estimate root growth. Specialised, are costly for reproduced pot experiments, and aren't promptly available for a nondestructive sampling of roots and soil. Here, Employing a Novel Cheap Rhizotron for Root Growth System Analyses on Plants. The root image securing using cheap technology Due to the inaccessibility of root systems, special methods are required to explore the dissemination and dynamics of roots. Utilizing this Rhizotron development, growth of the response the chickpea (Cicer arietinum L.) and Lentil (Lens culinaris Medik) under the hydroponic systems were explored. Significant differences in both architectural and morphological characteristics were observed among tested genotypes, especially for add up to root length, branch number, and particular root length and department thickness. It comes results illustrated that the framework was effective in screening root characteristics, permitting for rapid measurement of dimensional root architecture over time with negligible unsettling influence on plant growth and without destructive root sampling. The setup allows us to simultaneously characterize the root system and shoot development seedling stages. All components of the system are made from commodity components, locally available worldwide to facilitate the adoption of this affordable technology in low-income countries and detailed methods of construction allow researchers to construct and use similar Rhizotrons for experimental research.
\end{abstract}

Keywords: Rhizotron; Root; Hydroponic Transparency Paper; Chickpea; Lentil

\section{Introduction}

Roots of higher plants perform numerous imperative capacities: they supply anchorage, supply water, and minerals, and have a regulatory part moreover because they grow underground and aren't essentially accessible, roots are a lot of less totally considered than plant shoots [1]. Currently, understanding the effect of roots and rhizosphere characteristics on plant asset power is of the most elevated association [2]. The analysis of root system growth, root phenotyping, is imperative to educational efforts to improve plant asset acquisition from soils. In any case, root phenotyping remains challenging due to soil opacity and requires frameworks that optimize root permeability and picture securing. Nowadays, a number of methods have been used to gauge root development. These methods can be gathered into indirect and coordinate techniques $[3,4]$ both of which have points of interest and downsides. Indirect methods incorporate the utilizer of experimental models [5], estimations of nitrogen budget, and carbon budget [4]. Coordinate strategies can be classified into (i) destructive methods such as soil coring [6], consecutive soil coring in-growth cores [3,6], monoliths 
$[7,8]$ and soil pits $[9,10]$, and (ii) nondestructive in situ strategies counting isotope measurement [11], Rhizotrons [12] and minirhizotrons [13-15]. Rhizotrons and minirhizotrons are considered as effective approaches and are commonly utilized to characterize fine root development $[16,17]$.

A few non-destructive Rhizotron alternatives exist; those that do (strategies like X-ray computed tomography) taken a toll extreme sums of cash [18]. Rehashed non-destructive observations by and large involve the use of transparent interfaces, like Rhizotrons, minirhizotrons, and straightforward dividers. Minirhizotrons were, to begin with, portrayed by [12] as glass tubes inserted into the soil, closed at the foot, and fixed with a metal cover at the best. In that think about, roots of Lolium perenne $\mathrm{L}$. were watched by implies of a reflective and an electric bulb mounted at the conclusion of a metal pole. Rhizotrons extend in measure from underground windowed offices built beneath forests [19] to little plastic packs (i.e., seed germination pockets) utilized to consider herbaceous plants in a laboratory setting [20]. The most advantage of Mini Rhizotron systems is that rehashed root images can be recorded for expanded time periods [21]. Generally, the accessibility of inexpensive Mini-Rhizotrons, available off-the-shelf with negligible adjustment from non-specialist providers, seem to cultivate a more comprehensive and different community of researchers working on belowground forms in plant frameworks and seem research facility works out for undergrad and high school classrooms. We report here a straightforward A Hydroponic Rhizotron system that was created to provide an effective phenotyping platform for considering root engineering. This Hydroponic Rhizotron gives (1) non-destructive root morphometric estimations amid a try, (2) Rhizotron-specific autonomous experimental units, (3) simply get to for planting, (4) simply access forgather and (5) cheap Rhizotron plan suitable.

\section{Chickpea}

Chickpea (Cicer arietinum L.) is the second most widely developed pulse globally, with an include up to production of 14.2 million tons from a range of 11.6 million ha and an efficiency of $0.96 \mathrm{t} \mathrm{ha}^{-1}$ [22]. Its seeds are protein-rich options of animal protein in humans' diets. Chickpea may be a great source of protein $(20-22 \%)$ and is rich in carbohydrates (around 60\%), dietary fiber, minerals and vitamins $[23,24]$. Sustainable production of chickpea is challenged by climate changes, which are likely to extend production limitations and vulnerability of yields in the future. Edaphic stresses, such as drought and low-fertility soils, are the most factors limiting the production of chickpea as well as other major crops in numerous nations. The terminal drought is one of the major abiotic stresses constraining crop yield in chickpea [25].

Selecting and breeding cultivars with root systems that utilize water and nutrients effectively is an important methodology to extend trim adjustment to edaphic push [26] and Alteration to root framework engineering may progress alluring agronomic charac- teristics such as surrender, dry spell resilience, and resistance to nutrient insufficiencies [27].

\section{Lentil}

Lentil (Lens culinaris Medik) is a nutritious food legume. Lentil advanced and was tamed in Southwest Asia from where lentil development hence spread to reasonable biological systems in all continents. Breeding tall yielding lentil cultivars that minimize water utilization and have the foremost effective nitrogen utilize will be increasingly critical [28]. Future lentil cultivars must have both a compelling root system for capturing dampness whereas maximizing their nitrogen fixation. Roots frameworks affect nutrient and water uptake and work as sinks for photo acclimatizes and carbon inputs into the soil [29]. Although root frameworks shift from plant to plant in reaction to the environment and due to hereditary variety, the nearness of exceptionally fine roots (distance across $<0.5$ $\mathrm{mm}$ ) and/or fine roots (distance across $0.5-2.0 \mathrm{~mm}$ ) is a critical physiological component that determines most of the root length and root surface zone accessible for water and supplement take-up [30].

However, the efficiency of water extraction from soil depends on whether there is stored water save within the soil, or whether the water supply is driven by in-season precipitation [31]. In a perfect world, lentil varieties ought to have both deep root systems and roots that can spread over large soil volumes in arrange to capture surface water. The root system of cultivated lentil has been compared to those of oilseeds, other beat crops, and wheat The dispersion pattern of fine root traits such as root length, root surface region, root volume, and root diameter in cultivated lentil was different from those of other crops and thus seem to play a major role in water and nutrient take-up [29,31].

Seeds of the wild and cultivated lentil genotypes were scarified, washed in the bleach, and after that pre-germinated in a dark chamber at $22^{\circ} \mathrm{C}$. Seedlings with radicle length greater than $2 \mathrm{~cm}$ were selected after 3 days and after that transplanted into labeled tubes, were included in the soil surface following to the seedling in each tube. The experiment was a complete randomized block plan with 8 genotypes, two collect times (amid case filling and at full development), and four replicates. The temperature was set to $21^{\circ} \mathrm{C}$ day $/ 15{ }^{\circ} \mathrm{C}$ night day length set at $16 \mathrm{~h}$. The light bulbs within the room T-5 fluorescent bulbs and Driven light bars, $730 \mathrm{~mm}$ Far Red, Tube positions inside each piece were randomized at each weighing throughout the experiment to minimize position effects.

The objective of this study was to Novel Rhizotron and characterize genotypic variability in root traits in the chickpea collection and Lentil using a novel Rhizotron system use for root studies. This study provides detailed descriptions of the phenotypic variability and genetic diversity in root architectural traits in the chickpea core collection. 


\section{Plant Material and Seed Germination}

We present here an innovative design of hydroponic Rhizotrons adapted to chickpea (Cicer arietinum) and Lentil (Lens culinaris Medik). The setup allows us to simultaneously characterize the shoot development seedling. This system combines the advantages of hydroponics and rhizotrons. On one hand, roots grow in a controlled environment, ensuring the high reproducibility of the results. Root sampling is easy, typically for molecular and microscopic analyses. Being completely movable and low cost, it can be used in controlled cabinets. The hydroponic system was assembled by easily available components, i.e., a standard polycarbonate box (width $\times$ length $\times$ height $=31 \mathrm{~cm} \times 21 \mathrm{~cm} \times 22 \mathrm{~cm}$ ), C-Line's Transparency Films (8.5 $\times 11$ Inches) let you create overhead transparencies in a snap (Figure 1). The film is available for plain paper copiers, black and white laser printers, and inkjet printers. A drinking straw or drinking tube is a small pipe that allows its user to more conveniently consume a beverage. A thin tube of paper, bamboo, stainless steel, or plastic (such as polypropylene and polystyrene), or other material is used by placing one end in the mouth and the other in the beverage. Aquarium air pump (power $5 \mathrm{~W}$ and pressure $2 \mathrm{MPa} \times$ $0.02 \mathrm{MPa}$ ), flexible airline tubing (3mm in diameter), and tee connector. The frame hangs in a tank filled with a nutritive solution and is therefore slid into a slot of the tank cover. We sterilized all materials prior to the start of the experiment with either a dilute bleach solution. We scarified all chickpea and Lentil seeds used in this study sterilized them in ethanol. In Petri plate $(110 \mathrm{~mm} \times 25$ $\mathrm{mm}$ ), lined with filter paper and wetted with sterile water, 15 seed were placed. Petri plates were then placed in an incubator set at $28{ }^{\circ} \mathrm{C}$ for 4 days. Emerged plants (about 4 days after sowing) were carefully transplanted into the growth pouches. We then transplanted the seedlings into their respective growing treatment mini rhizotrons and allowed them to grow for six weeks. Seeds of Chickpea (MCC: Mashhad chickpea Collection) and Lentil (MLC: Mashhad Lentil Collection) genotype were used for this study. Hoagland solution was prepared as described [32] and then added to the hydroponic system. The hydroponic system was placed under controlled growth conditions in the greenhouse (16-h day/8-h night cycle, $28 \pm 2{ }^{\circ} \mathrm{C}$ and relative humidity was maintained at $\sim 60-70 \%$ ). We found that plants grown for 6 weeks showed maximum root trait diversity among the genotypes tested. At harvest, shoot height and leaf branch number per plant were measured. Root systems were photographed using a portable photographic system and taproot lengths were measured manually. Root subsamples were scanned in greyscale at 300 dpi using a desktop scanner. Root images were analyses using WinRHIZO Pro software. Data for various root traits, such as total root length, root surface area, root volume, average root diameter, and diameter class length (DCL, root length within a diameter class) were generated in WinRHIZO from images for each root section. The number of branches (primarily first order) in the first root section was counted manually from the images. Shoots and roots were then dried in an air-forced oven at $70{ }^{\circ} \mathrm{C}$ for $72 \mathrm{~h}$ and weighed to determine to shoot and root dry weights.
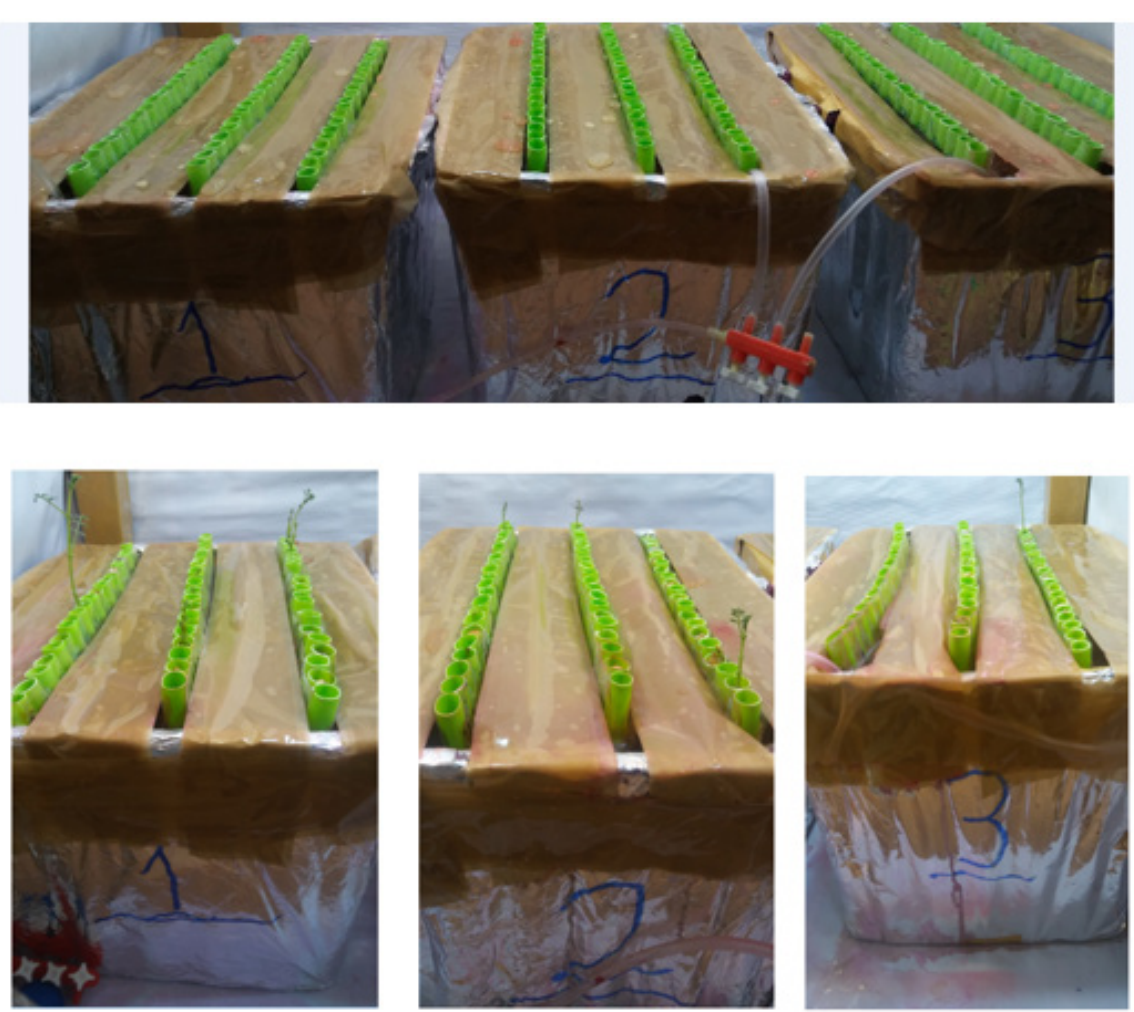

Figure 1: Schematic representation of the Hydroponic Rhizotron system. 


\section{Results}

Root morphological and architectural traits differed significantly among genotypes. Most chickpea genotypes developed roots vigorously. Genotypes exhibited large variation in rooting patterns and branching manner. Some genotypes had specific root traits such as long lateral roots, deeper roots with sparse and short branches, and fine roots (Figure 2). Shoot-related traits, i.e. shoot height, leaf branch numbers and shoot dry mass, were measured at harvest (42 days after sowing). ANOVA identified significant differences among genotypes in shoot height and shoot dry mass.
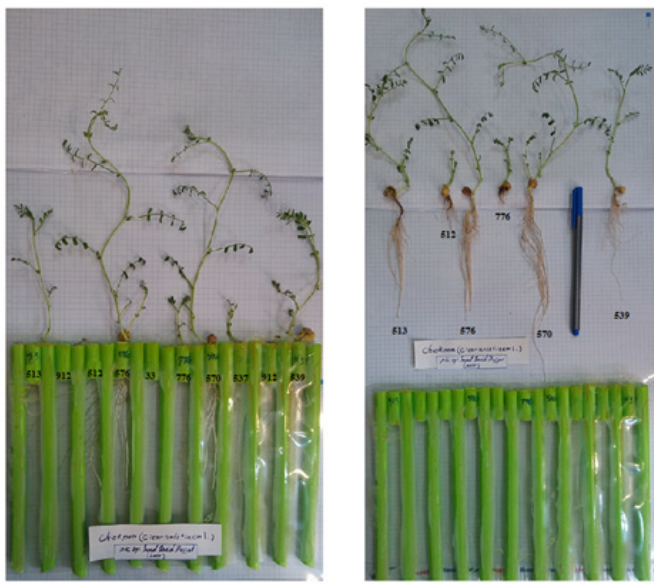

Figure 2: Root distribution of ten Chickpea genotypes at 6 weeks under the hydroponic system.

The 10 chickpea (MCC) and 19 Lentil (MLC) genotypes were significantly different in all root traits, such as root length, root surface area, root volume and root dry weight.

MCC570, MCC576, MCC513 and MCC539cultivars represented a group with robust root characters, with higher values for root length, root surface area, root volume and root dry weight. In contrast, MCC512 and MCC776 were identified as the small root system cultivars, with low values for all the root traits evaluated (Figures $3 \& 4)$.

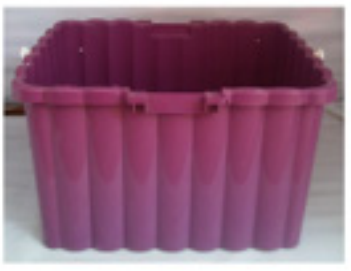

a

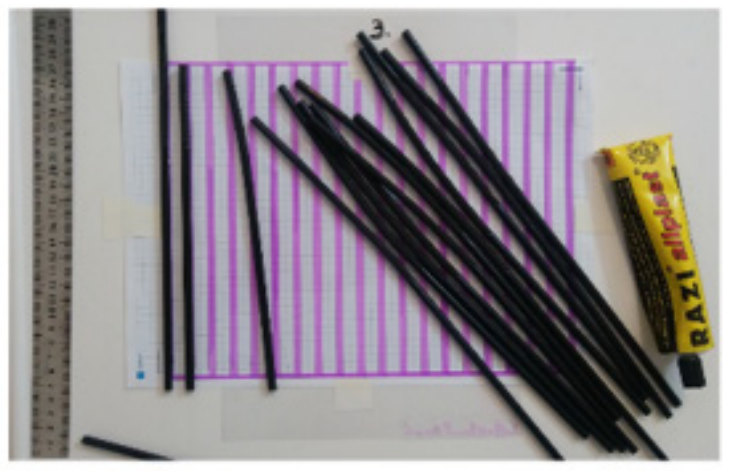

e
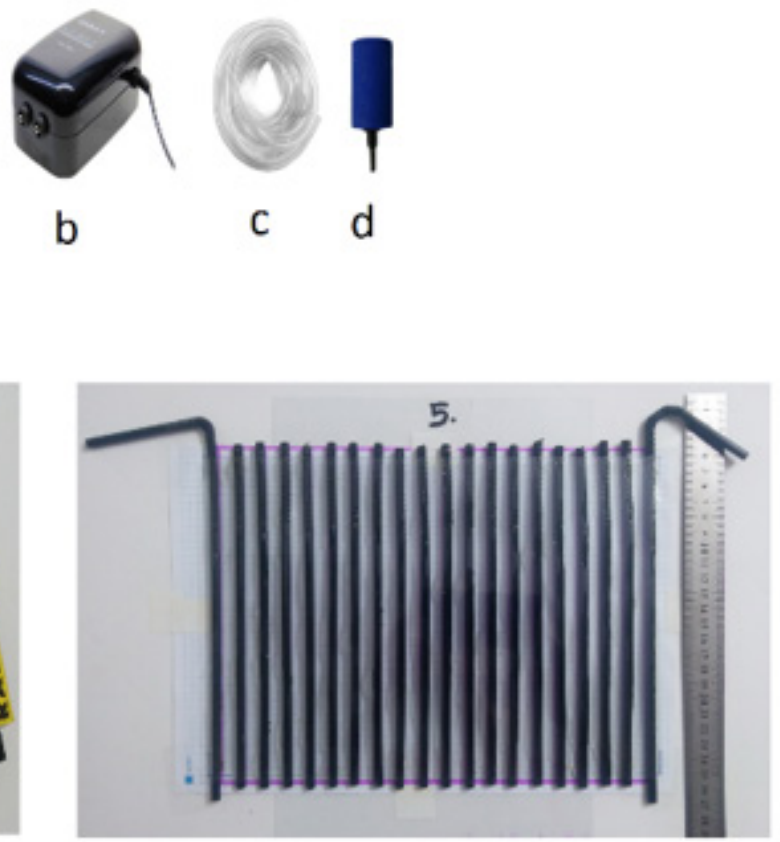

f

Figure 3: Schematic representation of the Hydroponic Rhizotron system: 10 Liter plastic mobile box; (b) Air pump aquarium; (c)Aquarium Pipes Vacuum; (d) Air Stones Vacuum (e) Drinking straw; (f) C-Line's Transparency Films. 

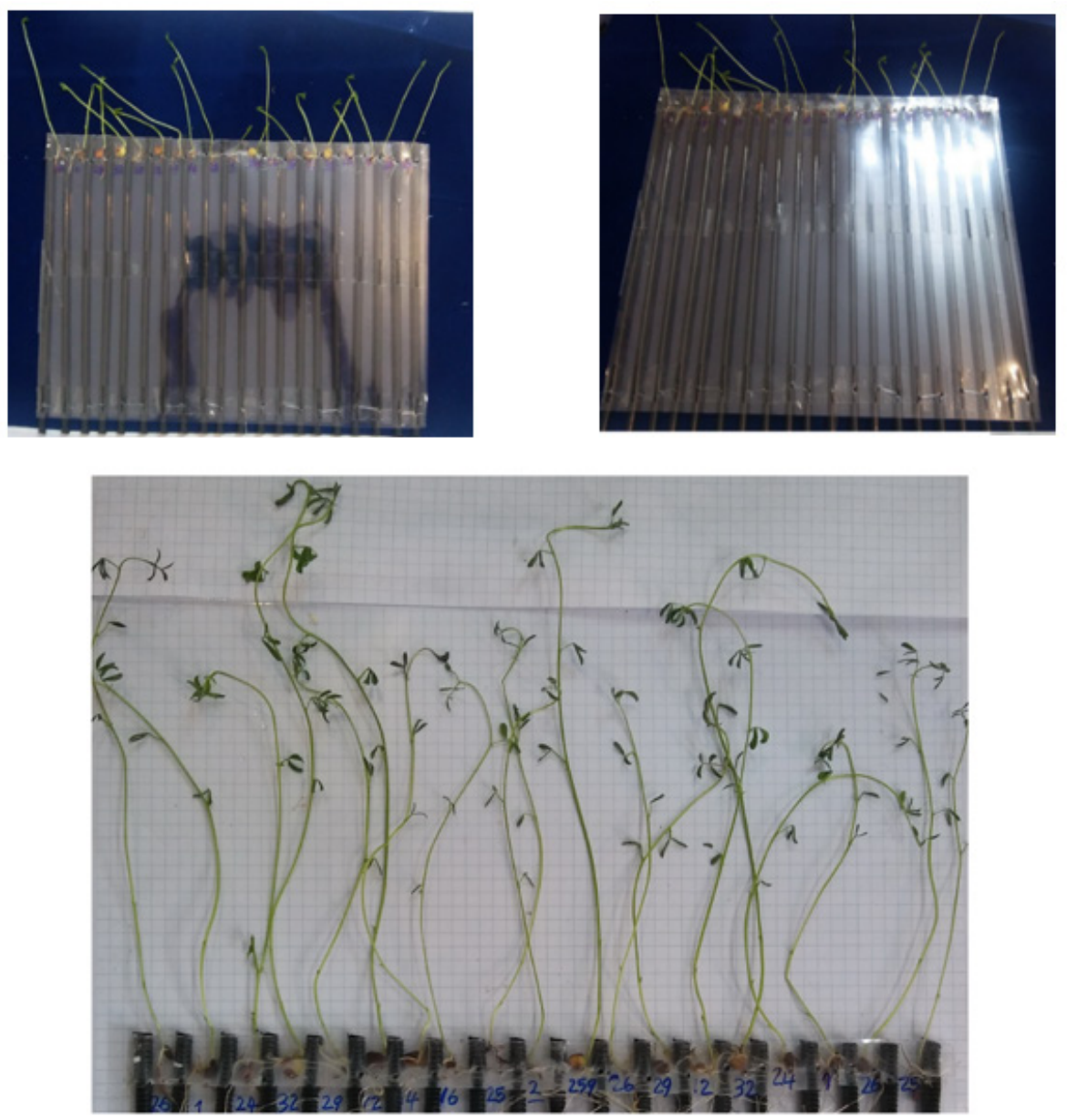

Figure 4: Example images showing root morphology and development of a Lentil (Lens culinaris Medik) genotypes grown in a Hydroponic Rhizotron experiment. Images were taken at (a) 1, and (b) 4 weeks after planting.

In The Lentil genotypes, MLC12, MLC24, MLC32 and MLC259 cultivars represented a group with robust root characters, with higher values for root length, root surface area, root volume and root dry weight. In contrast, MLC1, MLC2 and MLC25 were identified as the small root system cultivars, with low values for all the root traits evaluated (Figure 2). The main function of roots is to absorb of water and inorganic nutrients, thus support the physiological processes [31], and may indirectly contribute towards accumulation of organic substrates, growth and dry matter accumulation [33]. Thus, root dry weight might be an appropriate trait for chickpea root and Lentil root investigation under Novel Rhizotron conditions. Differences in all the above-ground characteristics studied, including stem height, stem diameter and leaf, and stem and shoot dry weight, were observed among the 10 chickpea and 19 Lentil genotypes.

The genotypes which exhibited superior root traits also showed superiority for shoot traits. MCC570 and MLC12 showed high values for plant height, leaf, stem, and shoot dry weight and stem diameter. Conversely, the small root system genotypes, such as MCC512, MCC776, and MLC1, MLC25 had low values for these aboveground traits (Figure 2).
In addition, the correlation between root and shoot traits had lower than the relationship among root traits. A related study has also been reported in rice which is in a monocot, the root system development was positively correlated with shoot mass production under water insufficient conditions [34].

Using a Novel Rhizotron for Root Growth System Analyses on Chickpea and Lentil Plants in hydroponic conditions is possibly an alternate method for root investigations, as it allows classifying the difference in root and shoots traits among chickpea and Lentil genotypes.

Under the hydroponic system, the root characteristic of peanut was positively correlated with that when grown under potted conditions [35] and Correlation between root traits in hydroponics and soil medium were also reported in wheat [36] and cowpea [37].

\section{Conclusion}

Studies on root growth have been numerous over the last decade and significant progress in evaluating root morphology has been made. However, research remains challenging and costly, especially in the natural environment. Many nondestructive methods, such as rhizotrons $[12,38]$ and minirhizotrons $[13,14]$. The abundance 
and diversity of root phenotyping methods are clear but the labor intensity and cost-limitation of effective Rhizotrons leave vital root measurements inaccessible to some plant biologists. Using a Novel Cheap Rhizotron described here offers a cost-effective and simple method for researchers to perform time-series experiments and incorporate large sample sizes into their experimental design. Due to the small size of these Rhizotrons, this protocol is best applied to young plants, and small herbaceous species and this system provide researchers the opportunity to phenotype root traits and the potential to study root-associated symbioses, at a relatively low cost. The system allows the non-destructive monitoring of the root system development and functioning. The system is capable of hosting plants of different rooting habits and until an advanced growth stage. The system is simple, easily implementable, modular, and adaptable to different types of image acquisition techniques. This method democratizes new research opportunities in the root microbiome for agriculture, community ecology, and evolutionary biology, particularly for researchers with limited resources. The greater effort of constructing and planting the Rhizotrons resulted in more accurate data, allowing a more appropriate statistical analysis.

\section{Acknowledgement}

The authors would like to thank Dr. Jafar Nabati for her excellent technical support.

\section{Conflict of Interest}

No conflict of interest.

\section{References}

1. Morris RJ, Fox RH, GA Jung (1982) Growth, P Uptake, and Quality of Warm and Cool-Season Grasses on a Low Available P Soil 1. Agronomy journal 74: 125-129.

2. Hinsinger P, Betencourt E, Bernard L, Brauman A, Plassard C, et al. (2011) $\mathrm{P}$ for two, sharing a scarce resource: soil phosphorus acquisition in the rhizosphere of intercropped species. Plant physiology 156: 1078-1086.

3. Vogt KA, Vogt DJ, J Bloomfield (1998) Analysis of some direct and indirect methods for estimating root biomass and production of forests at an ecosystem level. In Root demographics and their efficiencies in sustainable agriculture, grasslands and forest ecosystems. Springer Dordrecht 82: 687-720.

4. Hendricks JJ, Hendrick RL, Wilson CA, Mitchell RJ, Pecot SD, et al. (2006) Assessing the patterns and controls of fine root dynamics: an empirical test and methodological review. Journal of Ecology 94: 40-57.

5. Kurz WA, Beukema SJ, MJ Apps (1996) Estimation of root biomass and dynamics for the carbon budget model of the Canadian forest sector Canadian Journal of forest research 26: 1973-1979.

6. Box Jr JE, EL Ramsuer (1993) Minirhizotron wheat root data comparisons to soil core root data. Agronomy Journal 85: 1058-1060.

7. Majdi H, Smucker AJ, H Persson (1992) A comparison between minirhizotron and monolith sampling methods for measuring root growth of maize (Zea mays L.). Plant and Soil 147: 127-134.

8. Gautam TP, TN Mandal (2012) Effect of disturbance on fine root biomass in the tropical moist forest of eastern Nepal. Nepalese Journal of Biosciences 2: 10-16.

9. Heeraman DA, NJ Juma (1993) A comparison of minirhizotron, core and monolith methods for quantifying barley (Hordeum vulgare L.) and fababean (Vicia faba L.) root distribution. Plant and Soil 148: 29-41.
10. Addo-Danso SD, Prescott CE, AR Smith (2016) Methods for estimating root biomass and production in forest and woodland ecosystem carbon studies: A review. Forest Ecology and Management 359: 332-351.

11. Strand AE, Pritchard SG, McCormack ML, Davis MA, R Oren (2008) Irreconcilable differences: fine-root life spans and soil carbon persistence. Science 319: 456-458.

12. Bates GH (1937) A device for the observation of root growth in the soil. Nature 139: 966-967.

13. Germon A, Cardinael R, Prieto I, Mao Z, Kim J, et al. (2016) Unexpected phenology and lifespan of shallow and deep fine roots of walnut trees grown in a silvoarable Mediterranean agroforestry system. Plant and soil 401: 409-426.

14. Steinaker DF, SD Wilson (2008) Scale and density dependent relationships among roots, mycorrhizal fungi and collembola in grassland and forest. Oikos 117: 703-710.

15. West JB, Espeleta JF, LA Donovan (2004) Fine root production and turnover across a complex edaphic gradient of a Pinus palustris-Aristida stricta savanna ecosystem. Forest Ecology and Management 189: 397406.

16. Majdi H (1996) Root sampling methods-applications and limitations of the minirhizotron technique. Plant and Soil 185: 255-258.

17. Eissenstat DM, MM Caldwell (1988) Competitive ability is linked to rates of water extraction. Oecologia 75: 1-7.

18. Wu J, Y Guo (2014) An integrated method for quantifying root architecture of field-grown maize. Annals of botany 114: 841-851.

19. Potvin LR, EA Lilleskov (2017) Introduced earthworm species exhibited unique patterns of seasonal activity and vertical distribution, and Lumbricus terrestris burrows remained usable for at least 7 years in hardwood and pine stands. Biology and fertility of soils 53: 187-198.

20. You J, Hu Y, C Wang (2018) Application of seed germination pouch for culture and initial resistance screening of the soybean cyst nematode Heterodera glycines. Nematology 20: 905-909.

21. Hendrick RL, KS Pregitzer (1996) Applications of minirhizotrons to understand root function in forests and other natural ecosystems. Plant and Soil 185: 293-304.

22. Faostat F (2019) FAOSTAT statistical database. Publisher: FAO (Food and Agriculture Organization of the United Nations), Rome, Italy.

23. Williams PC, U Singh (1987) Nutritional quality and the evaluation of quality in breeding programs. In: Saxena, M.C. and Singh, K.B., Eds., The Chickpea, CAB International, Wallingford, pp. 329-356.

24. Jukanti AK, Gaur PM, Gowda CLL, RN Chibbar (2012) Nutritional quality and health benefits of chickpea (Cicer arietinum L.): a review. British Journal of Nutrition 108: 11-26.

25. Ludlow MM, RC Muchow (1990) A critical evaluation of traits for improving crop yields in water-limited environments. In Advances in agronomy Academic Press 43: 107-153.

26. Siddique KHM, Regan KL, Tennant D, BD Thomson (2001) Water use and water use efficiency of cool season grain legumes in low rainfall Mediterranean-type environments. European Journal of Agronomy 15: 267-280.

27. Tuberosa R, Salvi S, SANGUINETI MC, Landi P, et al. (2002) Mapping QTLs regulating morpho-physiological traits and yield: Case studies, shortcomings and perspectives in drought-stressed maize. Annals of Botany 89: 941-963.

28. Ladizinsky G (1997) A new species of Lens from south-east Turkey. Botanical Journal of the Linnean Society 123: 257-260.

29. Gan YT, Campbell CA, Janzen HH, Lemke R, Liu LP, et al. (2009) Root mass for oilseed and pulse crops: growth and distribution in the soil profile. Canadian Journal of Plant Science 89: 883-893.

30. Zobel RW, Y Waisel (2010) A plant root system architectural taxonomy: a framework for root nomenclature. Plant Biosystems 144: 507-512. 
31. Tron S, Bodner G, Laio F, Ridolfi L, D Leitner (2015) Can diversity in root architecture explain plant water use efficiency? A modeling study. Ecological modelling 312: 200-210.

32. Hoagland DR, DI Arnon (1950) The water-culture method for growing plants without soil. Circular. California agricultural experiment station 347.

33. Robertson MJ, Inman-Bamber NG, Muchow RC, AW Wood (1999) Physiology and productivity of sugarcane with early and mid-season water deficit. Field Crops Research 64: 211-227.

34. Kano M, Inukai Y, Kitano H, A Yamauchi (2011) Root plasticity as the key root trait for adaptation to various intensities of drought stress in rice. Plant and Soil 342: 117-128.
35. Girdthai T, Jogloy S, Kesmala T, Vorasoot N, Akkasaeng C, et al. (2010) Relationship between root characteristics of peanut in hydroponics and pot studies. Crop Science 50: 159.

36. Mian MAR, Nafziger ED, Kolb FL, RH Teyker (1993) Root growth of wheat genotypes in hydroponic culture and in the greenhouse under different soil moisture regimes. Crop Science 33: 283-286.

37. Ogbonnaya CI, Sarr B, Brou C, Diouf O, Diop NN, et al. (2003) Selection of cowpea genotypes in hydroponics, pots, and field for drought tolerance. Crop Science 43: 1114-1120.

38. Mao Z, Bonis ML, Rey H, Saint-André L, Stokes A, et al. (2013) Which processes drive fine root elongation in a natural mountain forest ecosystem?. Plant Ecology \& Diversity 6: 231-243. 